\title{
Climate change and agricultural vulnerability: a case study of rain-fed wheat in Kairouan, Central Tunisia
}

\author{
Raoudha Mougou • Mohsen Mansour • \\ Ana Iglesias · Rim Zitouna Chebbi · \\ Antonella Battaglini
}

\begin{abstract}
In the Maghreb and North African regions. the interannual climate variability causes severe impacts on agriculture through long drought episodes. Impacts are expected to increase due to projected climate change. Decreasing water availability will have a direct impact on the agriculture sector and could endanger the socioeconomic development and social stability in Tunisia where rain-fed agriculture represents the main occupancy and means of subsistence for the large rural population.
\end{abstract}

Keywords North Africa - Drought - Climate scenarios . Rain-fed wheat - Agricultural production - Agriculture Maghreb - Climate change - Climate impact

\section{Introduction}

In the Maghreb and North African regions, the interannual climate variability causes severe impacts on agriculture through long drought episodes. Recurrent droughts often affect entire countries over multiyear periods and can result in serious social problems caused by water scarcity and the intensive demand of water for agriculture. Impacts anticipated under projected climate change such as increasing rainfall variability, increasing temperature, increasing evaporation rate and water deficit pose a significant challenge to the Maghreb region. Mean temperatures of Morocco, Algeria and Tunisia are expected to rise by between 2 and $4^{\circ} \mathrm{C}$ until 2100 . Already by 2020 , rainfall is expected to drop by between 5 and $20 \%$ (Ministère de l'Environnement et de l'Aménagement du Territoire Tunisie 2002). Projected climatic conditions will have a direct impact on the agriculnure sector and could endanger the socioeconomic development and social stability in Tunisia where, mainly, rain-fed agriculture represents the main occupancy and means of subsistence for the large rural population. Indeed, the rural population, which accounts for over $53 \%$ of the total, is strictly dependent on the cultivated land which is usually equal or less than $5 \mathrm{ha}$. In this paper. we asses the risks imposed by projected climate change particularly for wheat production in the Tunisian central Kairouan region.

\section{Vulnerability}

Tunisia is highly vulnerable to water scarcity and water quality (Ministère de l'Environnement et de l'Aménagement du Territoire Tunisie 2002). Most of the water resources have medium to poor quality, and the salinity is 
often high. Water deficits and droughts are ongoing risks both for rain-fed and irrigated agriculture, which represents, respectively, 88 and $10 \%$ of the total agriculnural area.

The agricultural sector that provides approximately $13 \%$ of the national annual GDP (2004) to Tunisia is therefore particularly vulnerable to climatic changes also due to poor soils. limited ground and surface water. low rainfall and recurrent droughts. Projected climate change impacts. e.g., rising temperatures and decreasing precipitation, impose high risks for farmer's subsistence basis of nourishment and for the national economy.

Agriculture in Tunisia is mainly extensive, and efforts to intensify irrigated agriculture have been limited by climatic conditions and lack of water resources. Agriculture is the main user of land and the number one water consumer with a proportion of over $80 \%$ of the total national water consumption. The main rain-fed crops grown are cereals that represent about two-thirds of cultivated areas and $16 \%$ of agricultural production. fruit and olive trees covering circa $40 \%$ of cultivated areas and representing $28 \%$ of agricultural production and $60 \%$ of exported foods. These crops are significant for the Tunisian national economy as they are important export goods and also secure almost all national consumer needs for wheat and barley. The socioeconomic developments could be negatively influenced by projected more irregular and lower rainfall especially in combination with already fragile ecosystems and limited natural resources. Additionally, the expected population increase of about 13 millions by 2025 . the urbanization process and industrial development. will contribute to an intensified water demand and competition among water users. A further increase in instability of agricultural production and food supplies is therefore likely.

The Tunisian central region is a climatic transition zone between the Mediterranean zone and the Sahara region with high climatic variability (Benzarti 1996). Hot conditions are frequent throughout the wheat growing season from November to April (Mougou and Henia 1996). Severely dry years, with a deficit of evapotranspiration over $50 \%$, are frequent in this region, representing a permanent risk for the rain-fed agriculture. Rain-fed wheat production in the Tunisian central region Kairouan and its four districts (Ouslatia, Sbikha. Haffouz and Kairouan) is the subject analyzed in this study. The analysis is neither representative for all Tunisian microclimates nor applicable to every respective agricultural system. Instead, it wants to point out the specific vulnerability to climate change of a sensitive region and contribute to better understand impacts of climate change in a continent where the vulnerability assessment is particularly uncertain due to high variability and limited observation networks.

\section{Materials and methods}

Climatic data series (minimum and maximum temperature, minimum and maximum humidity, rainfall, wind speed, solar radiation) from 1950 to 2004 (or for shorter periods when the complete data series were not available) were analyzed. Wheat production data series used in this study cover the period from 1980 until 2000 and include data on cultivated areas. sown areas and non-harvested areas and yield under rain-fed conditions. The Penman-Monteith equation for evapotranspiration (Allen et al. 1998) was applied to evaluate the current water deficit in the Kairouan region.

In the most stressed areas, the water balance deficit results in crop failures during severe drought years. To emphasize the underlying agroclimatic drought episodes that affect the wheat production in the Kairouan region. the agroclimatic water balance (rainfall minus wheat water requirements) was evaluated. Wheat water requirements used represent mean water consumption evaluated experimentally during 1989-1993 period (Nasr et al. 2001), and it has been calculated for the wheat growing season period from November to April. Given that the water balance is not uniform across the Kairouan region and there are large variations in the crop growing conditions within the region. the water balance of four sites within the Kairouan region was taken into account: Kairouan, Ouslatia, Sbikha and Haffouz.

For the agroclimatic characterization of actual temperatures and climate change conditions, we calculated and compared the actual and the predicted climatic indices in order to show how the climate is changing in this region. Standard daily meteorological data were used (temperature, rainfall, relative humidity) to compute the Martonne aridity index, the Emberger coefficient and the Gaussen Ombrothermic index.

Projected climate change impacts on climatic indices, reference evapotranspiration. wheat yield and wheat growing season duration have been assessed according to different climate scenarios. For a projected temperature increase by the year 2100 , we used the IPCC scenarios: $1592 \mathrm{c}$ $\left(\mathrm{T}+1.3^{\circ} \mathrm{C}\right)$. IS92a $\left(\mathrm{T}+2^{\circ} \mathrm{C}\right)$ and IS92e $\left(\mathrm{T}+2.5^{\circ} \mathrm{C}\right)$ (Leggett et al. 1992). We also used a $\mathrm{T}+4^{\circ} \mathrm{C}$ scenario, given that the SRES scenarios predict at global scale a temperature increase by $1.4^{\circ} \mathrm{C}$ to $5.8^{\circ} \mathrm{C}$ (IPCC $200 \mathrm{l}$ ).

To evaluate climatic index under climate change conditions for projected rainfall, we used scenarios that expect for Morocco, Algeria and Tunisia, a decrease of $5-20 \%$ by the year 2020 (Regional Coordination of the UNDP/GEF RAB/94G31 Project 2002). We also compared the experimental growing season duration of wheat to the simulated duration under temperature increase conditions using previous temperature increase scenarios. 
The IS92a and IS92c scenarios have been used as input for MAGICC/SCENGEN simulations (Santer et al. 1996; Wigley and Raper 1992: IPCC 1996; Raper et al. 1996; Hulme et al. 2000). Results were used in a Decision Support System for Agrotechnology Transfer (DSSAT) application to evaluate climate change impact on wheat production.

\section{Climate of the Kairouan region}

In Tunisia, severely dry years (deficit of annual evapotranspiration $>50 \%$ ) and drought persistency are more frequent in the south and in the center than in the north (Louati et al. 1999). The climate of central Tunisia and especially in the Kairouan region is characterized by a large year-to-year and intra-year variability of rainfall. This variability combined with water deficit and drought episodes negatively influences the rain-fed agriculnural production and leads to irregular yields.

Data series from 1951 to 2008 collected at the Tunisian National Institute of Meteorology show a significant yearto-year variation in rainfall. The average annual rainfall is $282 \mathrm{~mm}$ (maximum $734.4 \mathrm{~mm}$; minimum $133.1 \mathrm{~mm}$ ) with the summer months of June, July and August recording only $12.2,2.5$ and $16.4 \mathrm{~mm}$. respectively. High precipitations can be recorded in the winter months (e.g.. mean values for October: $48.8 \mathrm{~mm}$ ). A monthly and seasonal variability of rainfall is often registered in the region with a coefficient of variation of 0.84 in the summer season (Henia 1993)

Temperature data series from 1951 to 2008 show annual maximum and minimum mean temperatures of. respectively, 15.1 and $27^{\circ} \mathrm{C}$. The maximum absolute temperature can reach $48.1^{\circ} \mathrm{C}$ in August. The minimum absolute temperature can reach $-4.2^{\circ} \mathrm{C}$ in January.

High temperatures are often combined with the sirocco, a very dry wind blowing from the Sahara, which can last for 12 successive days. Annual mean sirocco days recorded during 1975 to 1995 were 41 (minimum 13; maximum 60) (Mougou and Henia 1998). Solar radiation is very high and can exceed $3000 \mathrm{~h}_{\text {year }}{ }^{-1}$. Evaporation is also high. reaching an annual average of $1390 \mathrm{~mm}$ (Abou-Hadid 2006).

Warming at Kairouan during the last 50 years (1951-2002) is statistically significant $\left(0.29^{\circ} \mathrm{C} / 10\right.$ years) (Abou-Hadid 2006). Also minimum temperatures have increased significantly (Abou-Hadid et al. 2003). Previous studies carried out in Tunisia on longer data sets (1901-1990) have failed to identify a statistically significant trend in temperature increase (Labben et al. 1996). Likewise, rainfall data for the same period across the great geographic regions of Tunisia do not reveal any significant trend (Sakkis et al. 1994).

\section{Implications of temperature increase and rainfall decrease on the water balance}

An indicator for the implications of a combined increase in temperature and decrease in precipitation can be gained from the use of aridity indices. If the Martonne aridity index is calculated based on the local 2-C temperature increase and $5 \%$ rainfall decrease. then there is a trend toward a shift from a semiarid to an arid climate in the Kairouan region by year 2100 . Similar results are obtained by using the Emberger coefficient when calculated based on the 1.3-C temperature increase and 5\% rainfall decrease. If the climate changes in this direction (temperature increase and rainfall decrease), the ombrothermic diagrams show a lengthening of dry periods. which become more frequent and longer. Whatever temperature scenarios. dry period spreads out over the whole year if there is $20 \%$ rainfall decrease.

Daily climate data were used to calculate the reference evapotranspiration $\left(\mathrm{ET}_{0}\right)$ at present and in the year 2100 climatic conditions. Using IPCC scenarios $\left(+1.3^{\circ} \mathrm{C}\right.$. $\left.+2.0^{\circ} \mathrm{C},+2.5^{\circ} \mathrm{C}\right)$ and IPCC SRES scenarios $\left(+4^{\circ} \mathrm{C}\right)$, the rate of $\mathrm{ET}_{0}$ increase by year 2100 compared with actual values $(1872 \mathrm{~mm})$ is equal to $3.1 \%$ for the optimistic scenario $\left(+1.3^{\circ} \mathrm{C}\right), 4.5 \%$ when there is an increase of $2^{\circ} \mathrm{C}$ and $9.4 \%$ for the pessimistic scenarios $\left(+4^{\circ} \mathrm{C}\right)$.

The projected evapotranspiration increase will further aggravate the water deficit for rain-fed and irrigated agriculture in Tunisia (Lebdi 2002). For the rain-fed cereals, an increase in temperatures will intensify evaporation and consequently the water deficit and water requirement.

In the Kairouan region. by the year 2100 , the rate of increase in maximum wheat evapotranspiration (ETMW) will represent $11.3 \%$ of the actual wheat water requirement, and the water deficit increase will be $15.2 \%$ higher than the acnual wheat water deficit $(523.6 \mathrm{~mm})$ for the high scenario $\left(+4^{\circ} \mathrm{C}\right)$.

\section{Impacts on rain-fed wheat production under rainfall variability and water deficit}

Both yields and harvested areas are correlated with the total amount of rainfall and the rainfall in March. The regression coefficients (Table 1) are highly significant for the four sites. The analysis was carried out in the Ouslatia, Sbikha. Haffouz and Kairouan districts to represent different cultivation systems, soils and spatial variability of rainfall. 
Table 1 Regression coefficients of durum wheat yields and harvested areas according to total rainfall for the 1995-2003 period in Kairouan, Sbikha, Haffouz and Ouslatia

\begin{tabular}{llll}
\hline 1995/2003 & \multicolumn{2}{l}{ Regression coefficient } \\
\cline { 2 - 4 } & $\begin{array}{l}\text { Rate harvested } \\
\text { areas/total rainfall }\end{array}$ & $\begin{array}{l}\text { Yield/total } \\
\text { rainfall }\end{array}$ & $\begin{array}{l}\text { Yield/rainfall } \\
\text { March }\end{array}$ \\
\hline Kairouan & 0.92 & 0.84 & 0.87 \\
Sbikha & 0.95 & 0.92 & 0.65 \\
Haffouz & 0.92 & 0.81 & 0.80 \\
Ouslatia & 0.87 & 0.85 & 0.67 \\
\hline
\end{tabular}

For the period 1995-2003, the regression coefficients between total harvested area and total rainfall, yields and total rainfall, yields and rainfall of March were calculated for the four sites. Table 2 shows that yields for wheat is positively correlated with rainy years (1995/1996 and $2002 / 2003$ ), while the correlation is negative for dry years (1996/1997 and 2001/2002). Rainy years have an annual mean rainfall that is $>$ than $233 \mathrm{~mm}$; dry years' annual mean rainfall is $<130 \mathrm{~mm}$.

Cereal yields in the northern region of the country are larger since the precipitation is larger, for example in Béja, average cereal yield is 20.09 quintals ha ${ }^{-1}$. If only irrigated cereals are considered, yields can reach 80 quintals $\mathrm{ha}^{-1}$ in other areas of Tunisia (Abou-Hadid 2006).

Similar results were also obtained by correlating monthly rainfall data during the farming season from September to April with wheat yields (Figs. 1, 2), thus confirming the results from Louati et al. (1999) which indicate that the harvest output is strictly dependent on autumn rainfall.

Results of calculated wheat water balance (rainfall minus wheat water consumption) show that wheat has always been grown under drought conditions in the Kairouan region as the wheat water requirements are almost never satisfied for rain-fed agriculture. Wheat cultivations suffered a substantial water deficit balance during almost all growing periods in the four studied subregions (Fig. 3). Water deficits occur from December to April. The water balance is positive only in November, because of the low water requirements that can be satisfied by soil water even if there is no rain.

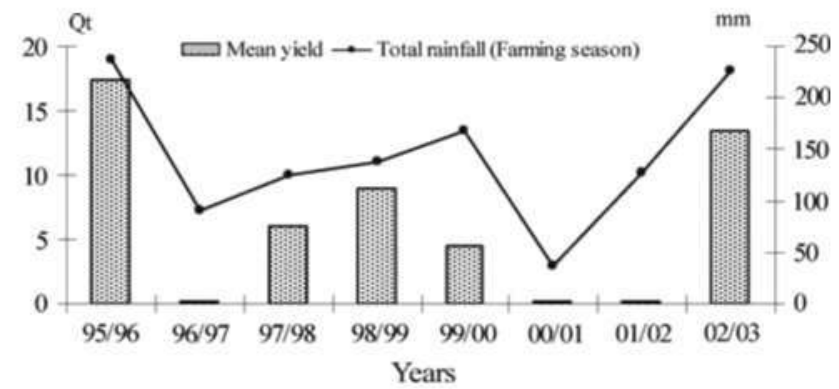

Fig. 1 Durum wheat yield evolution according to total rainfall in Kairouan region (1995-2003)

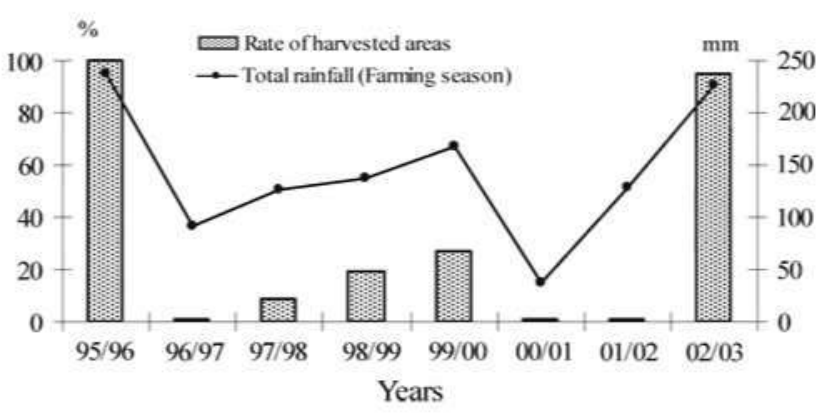

Fig. 2 Rate of durum wheat harvested areas according to total rainfall in Kairouan region (1995-2003)

The quantitative analysis showed that, added to the variability of rainfall, the high evapotranspiration and water needs will increase the amount of water deficit and will certainly reduce agricultural production and yields.

In the Kairouan region, projected climate change will result in worsening conditions for rain-fed crops. Temperature increase and water decrease could affect photosynthesis, the vegetative development of plants, and the length of the vegetative cycle and consequently yields. The whole plant metabolism could change.

Figure 4 shows results of simulations run with Decision Support System for Agrotechnology Transfer DSSAT model and field experimental data (1996-1997) under climate change conditions. A substantial decrease in crop yields should be expected under different levels of temperature (T) increase and rainfalls $(R)$ decrease.
Table 2 Mean harvest during rainy and dry years from 1995 to 2003 in Kairouan, Sbikha, Haffouz and Ouslatia

\begin{tabular}{|c|c|c|c|c|c|}
\hline & \multicolumn{2}{|c|}{$\begin{array}{l}\text { Rainy years (1995/1996 and } 2002 / \\
2003)\end{array}$} & \multicolumn{2}{|c|}{$\begin{array}{l}\text { Dry years }(1996 / 1997-2001 / \\
2002)\end{array}$} & \multirow{2}{*}{$\begin{array}{l}\text { Yield increase during } \\
\text { rainy years in relation } \\
\text { to dry years }(\%)\end{array}$} \\
\hline & $\begin{array}{l}\text { Mean } \\
\text { rainfall (mm) }\end{array}$ & $\begin{array}{l}\text { Mean } \\
\text { yields (qt) }\end{array}$ & $\begin{array}{l}\text { Mean } \\
\text { rainfall }(\mathrm{mm})\end{array}$ & $\begin{array}{l}\text { Mean } \\
\text { yields (qt) }\end{array}$ & \\
\hline Kairouan & 231.55 & 15.5 & 114.2 & 6.5 & 138 \\
\hline Sbikha & 275.2 & 17.5 & 112.6 & 6.3 & 178 \\
\hline Haffouz & 269.15 & 14 & 99.1 & 6 & 133 \\
\hline Ouslatia & 317.7 & 15.5 & 130.9 & 8.6 & 80 \\
\hline
\end{tabular}




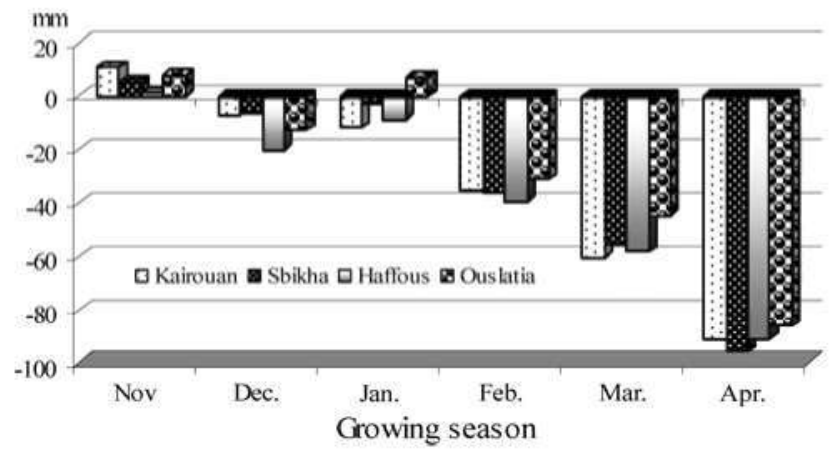

Fig. 3 Mean monthly wheat water balance (1979-2000)

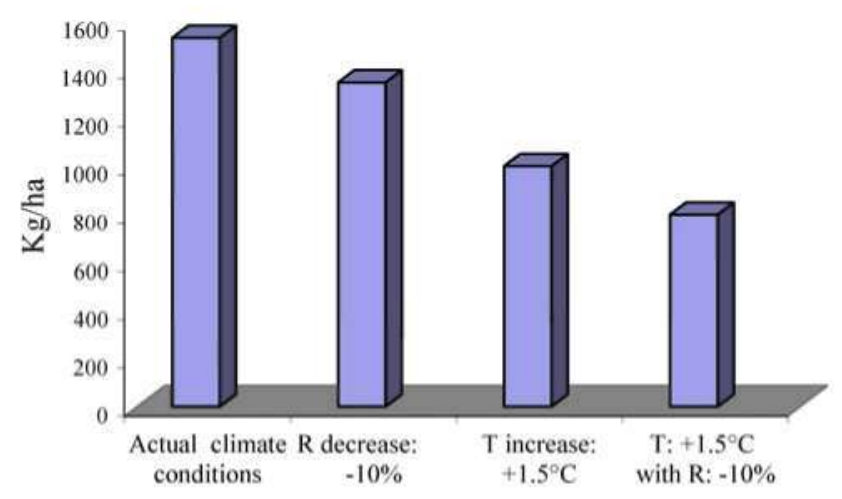

Fig. 4 DSSAT simulations for wheat yields under different climatic conditions

The length of the wheat growing season was estimated for different levels of temperature increase as projected by the IPCC scenarios: 1.3-C temperature increase for IS92c, $2^{\circ} \mathrm{C}$ for IS92a, $2.5^{\circ} \mathrm{C}$ for IS92e and $4^{\circ} \mathrm{C}$. Results show a shortening of the growing season that varies in relation to the temperature increase. In actual climate conditions and in the experimental field, the wheat growing duration is equal to 193 days; by 2100 , the wheat growing season would be shortened by 10 days for $1.3-\mathrm{C}$ temperature increase conditions, by 16 days for $2^{\circ} \mathrm{C}$, by 20 days for $2.5^{\circ} \mathrm{C}$ and by 30 days for $4^{\circ} \mathrm{C}$.

Using the Météo-France ARPEGE-Climate atmospheric model (Version 4) (Déqué 2007), similar results have been found by other Tunisian studies. The wheat crop cycle mean duration is reduced approximately 25 days in Kairouan region (Lhomme et al. 2009). The shortened cycle has detrimental effects on several development stages such as flowering and grain-filling, thus ultimately leading to reduced yields and quality.

\section{Conclusion}

Water resources for agriculture in Tunisia are scarce and, due to arid and semiarid climatic conditions, the rate of evapotranspiration is high. Agriculture outputs depend strongly on reliable and regular precipitations. Projected warming, changes in climate variability and precipitation patterns, combined with higher evapotranspiration rates, could severely disturb agricultural practices and translate in crop failure, crop quality and quantity losses and lower the level of food security (according to the Human Development Index (HDI), North Africa and Tunisia are considered to have a medium-low food security). These factors could have high social and economical consequences for the country that is highly dependant on its agricultural output for economic growth and employment.

The case study in the Kairouan region indicates that any increase in temperature during the wheat growing season will have a direct impact on water availability and on crop production. It is expected that wheat production in areas with similar climatic and geographical conditions may be affected in similar ways. It is therefore essential that projected levels of temperature increase and other climate change for Tunisia are carefully considered due to the potentially very severe consequences for the socioeconomic development and social stability. Increased food insecurity in the rural areas may further contribute to urbanization and migration toward richer areas and/or countries, thus further increasing competition over resources and wealth. In a country with limited opportunities and high unemployment, agriculture output is essential to provide economic security to rural population. It is therefore essential to integrate adaptation strategies to climate change impacts into the national policies for sustainable development.

Tunisia's government set up a management strategy for the sustainable use of available resources. With groundwater and renewable water resources being scarce, improved irrigation management is possible only by using new agricultural technologies and adopting a better understanding of yields responses to changing climate variability and water scarcity. New agricultural techniques will need to be developed and introduced to farmers to be able to cope with projected change. Farmers will need assistance in order to be able to adapt to climate changing conditions and in order to be able to build up capacity to minimize crop sensitivity to climate change and effective water management in stress conditions.

Furthermore, as suggested by "The national communication of Tunisia under the UNFCCC" and related to Article 2 of the UNFCCC (1992), there is a need for decision makers to integrate climatic change in the development programs and to raise the entire population's awareness of climate change. More research activities on the topic of climate change and its impacts on agricultural production are needed, and it would good to involve stakeholders at different levels and NGOs in the conception of management programs for natural resources. 
Acknowledgments We would like to thank Raoudha Mougou for leading the work, which delivered this paper. We regret that the paper is only published after her sudden death.

\section{References}

Abou-Hadid AF (2006) Assessment of impacts, adaptation, and vulnerability to climate change in North Africa: food production and water resources. Project no. AF 90. The International START Secretariat, Washington

Abou-Hadid A, Mougou R, Mokssit A, Iglesias A (2003) Assessment, impacts, adaptation, and vulnerability to climate change on North Africa: food and water resources. Tunisian part of AIACC AF90 semi annual progress report. AIACC regional studies. Assessments of impacts and adaptations to climate change (AIACC) in multiple regions and sectors

Allen RG. Pereira LS, Raes D, Smith M (1998) Crop evapotranspiration guidelines for computing crop water requirements. FAO irrigation and drainage paper, vol 56. Food and Agriculture Organization of the United Nations, Rome

Benzarti Z (1996) La maitrise des eaux de surface: l'expérience des lacs collinaires en Tunisie. La Revue des Géographes Tunisiens 4:15

Déqué M (2007) Frequency of precipitation and temperature extremes over France in an anthropogenic scenario: model results and statistical correction according to observed values. Glob Planet Change 57(1-2): 16-26

Henia L (1993) Climat et bilan de l'eau en Tunisie. Essai de régionalisation climatique par les bilans hydriques. Publications de l'Université de Tunis I Deuxième série Geographie XXVI

Hulme M, Wigley TML, Barrow EM, Raper SCB, Centella A, Smith $S J$, Chipanshi $A C(2000)$ Using a climate scenario generator for vulnerability and adaptation assessments: MAGICC and SCENGEN, vol 2.4. Climatic Research Unit, University of East Anglia, Norwich

IPCC, 1996: Climate Change 1995: The Science of Climate Change. Contribution of Working Group I to the Second Assessment Report of the Intergovernmental Panel on Climate Change, J.T. Houghton. L.G. Meiro Filho, B.A. Callander, N. Harris, A. Kattenberg, K. Maskell, Eds., Cambridge University Press, Cambridge

IPCC, 2001: Climate Change 2001: The Scientific Basis. Contribution of Working Group I to the Third Assessment Report of the Intergovernmental Panel on Climate Change, J.T. Houghton, Y. Ding, D.J. Griggs, M. Noguer, P.J. van der Linden, X. Dai, K. Maskell, C.A. Johnson, Eds., Cambridge University Press, Cambridge

Labben Y, Hsoumi N, Kerkeni H, Fray B (1996) Evolution de la température en Tunisie. Variabilité du climat et stratégies d'adaptation humaines en Tunisie. Publications de l'Université de Tunis I Série colloque 7ème VI:125-136
Lebdi F (2002) Irrigation advisory services in Tunisia. Food and Agriculture Organization of the United Nations/Ministère de l'Agriculture, Hammamet

Leggett J, Pepper WJ, Swart RJ (1992) Emissions scenarios for IPCC: an update. In: Houghton JT, Callander BA, Varney SK (eds) Climate change 1992: the supplementary report to the IPCC scientific assessment. Cambridge University Press, Cambridge. pp 71-95

Lhomme J, Mougou R, Mansour M (2009) Potential impact of climate change on durum wheat cropping in Tunisia. Clim Change 96:549-564

Louati MH, Khanfir R, Alouini A, El Echi ML, Frigui L, Marzouk A (1999) Guide pratique de la gestion de la sécheresse en Tunisie. Approche méthodologique. Ministère de l'Agriculture, Tunis

Ministère de l'Environnement et de l'Aménagement du Territoire Tunisie (2002) Vulnerability of the Maghreb Region to Climate Change, and Needs for Adaptation. UNDP/GEF \& Ministère de l'Environnement et de l'Aménagement du Territoire Tunisie, Tunis

Mougou R, Henia L (1996) La sécheresse agroclimatique en Tunisie. Cas de la culture du blé. La Revue des Géographes Tunisiens $4: 1-17$

Mougou R, Henia L (1998) Contribution à l'étude des phénomènes à risques en Tunisie. Cas du sirocco. Les Publications de l'Association Internationale de Climatologie 9

Nasr Z, Zairi A, Ben Nouna B, Ouslati T (2001) Détermination de la consommation en eau journalière par bilan d'énergie des cultures annuelles (blé et pomme de terre). Evolution avec la biomasse et application au pilotage des irrigations. Les Annales de l'INRGREF special edition:114-125

Raper SCB, Wigley TML. Wanick RA (1996) Global sea level rise: past and future. In: Milliman J. Haq BU (eds) Sea-level rise and coastal subsidence: causes consequences and strategies. Kluwer, Dordrecht, pp 11-45

Regional Coordination of the UNDP/GEF RAB/94G31 Project (2002) Vulnerability of the maghreb region to climate change, and needs for adaptation (Algeria, Morocco, Tunisia). Ministère de l'Aménagement du territoire, de l'Urbanisme, de l'Habitat et de l'Environnement, Rabat, Morocco

Sakkis N, Ennabli N, Slimani MS, Baccour H (1994) La pluviométrie en Tunisie a-t-elle changé depuis 2000 ans? Recherche de tendance et de cycles dans les séries pluviométriques. Institut national de la météorologie, Tunis

Santer BD. Wigley TML, Schlesinger ME, Mitchell JFB (1996) Developing climate scenarios from equilibrium GCM results. MPI Report 47. Hamburg

UNFCCC (1992) The United Nations Framework Convention on Climate Change

Wigley TML, Raper SCB (1992) Implications for climate and sealevel of revised IPCC emissions scenarios. Nature 357(6376): 293-300 